\title{
Histopathological Characterization of Soft Palate in Brachycephalic Syndrome in Pugs: A Review of 12 Cases
}

\author{
B. Prakash Kumar ${ }^{1 *}$, Mala Shammi ${ }^{1}$, C. Ramani $^{1}$, Geetha Ramesh $^{2}$ and \\ Balagangatharathilagar $^{3}$ \\ ${ }^{1}$ Department of Veterinary Surgery and Radiology, ${ }^{3}$ Department of Clinical Medicine, Madras \\ Veterinary College, Chennai, India \\ ${ }^{2}$ Director of Distance Education, Tanuvas, Chennai, India \\ *Corresponding author
}

\section{A B S T R A C T}

Keywords

Brachycephalic

dogs,

Histopathology of soft palate, Diode

laser

staphylectomy, $\mathrm{CO}_{2}$ laser staphylectomy

Article Info

Accepted:

12 December 2020

Available Online:

10 January 2021
The present study was conducted to evaluate the histological features of elongated soft palate in dogs affected with brachycephalic syndrome. Soft palate samples were collected from dogs which underwent surgical correction of elongated soft palate. Histological observations of brachycephalic soft palate in this study were edema of the lamina propria, superficial epithelial hyperplasia, interfibrillar matrix swelling, hyperplasia of mucous gland and structural degeneration of muscle fibers. Histological study indicate that the increased thickness of the elongated soft palate in dogs with brachycephalic airway syndrome was not due to muscle hypertrophy or fat deposition but is instead due to significantly increased stroma within the lamina propria, edema and increased proportion of salivary tissue. Hence multifactorial changes are responsible for elongation and thickening of soft palate in brachycephalic dogs.

\section{Introduction}

Brachycephalic air way syndrome is defined as partial obstruction of upper airway of dogs and cats having shortened head due to selective breeding. Obstruction is due to anatomical abnormalities of stenoticnares, elongated soft palate, everted laryngeal saccules and hypoplastic trachea (Poncet et al., 2005).
Surgical correction of the elongated soft palate has been reported since 1942 (Farquharson1942). Clinical signs include dyspnea, snoring, stridor, exercise intolerance, regurgitation, vomiting, cyanosis, syncope and collapse (Gruenheid et al., 2018) $80 \%$ of dogs with elongated soft palate were brachycephalic and was considered as one of the most common abnormality found in brachycephalic airway syndrome. 
The free border of soft palate extend beyond the glottal opening and tip of the epiglottis (Davidson et al 2001). In brachycephalic dogs due to shortening of viscerocranium the soft palate extends 1-3 $\mathrm{mm}$ beyond the tip of epiglottis and is considered as elongated soft palate (Lodato and Hedlund 2012).

The proximal portions of the respiratory (nasopharynx) and digestive systems (Oropharynx) are separated by soft palate (velum palatinum). Soft palate overlaps epiglottis as it continues caudally to a variying degrees and synchronized functioning of the soft palate and epiglottis is important for both swallowing and respiration. An elongated and thickened soft palate causes obstruction to respiration. Obstructive sleep apnea syndrome is a similar condition in humans associated with the abnormal functioning of soft palate along with other factors (Hamans et al., 2000; Berger et al., 2002).

The increasing popularity of brachycephalic breeds as pets has led to rise in the occurrence of brachycephalic obstructive air way syndrome. Different surgical techniques have been done to addresss the different components of the air way obstruction. Resection of the soft palate (staphylectomy) is done to correct the elongated soft palate. Studies on the histopathology of the elongated soft palate are few and so far to the best knowledge the author there are no publications in this countries till date. In the present study emphasis was given to understand the histological changes of the soft palate in relation to its physiological function and its pathological changes in relation to respiration.

\section{Materials and Methods}

Samples collected from the dogs presented with brachycephalic syndrome treatment to
Madras Veterinary College Teaching hospital. All dogs had a complete clinical examination of an upper airway including radiography and Computed tomography under general anesthesia. Soft palate samples collected from brachycephalic dogs in $10 \%$ neutral formalin after surgical resection using carbon dioxide laser and conventional techniques. After fixing in formalin the soft palate sample was divided into two equal parts and dehydrated in ethanol and embedded in paraffin.

4-6 $\mu \mathrm{m}$ thick sections are used for histological examination after staining with hematoxylin and eosin technique (H\&E) and examined under microscope (Arrighi 2011). Computerassisted image acquisition was done with Olympus digital camera with DP software for series of sections.

\section{Results and Discussion}

All the specimens in the present study showed hyperplasia of the superficial epithelia, extensive swelling of interfibrillar matrix and edema of the lamina propria, mucousgland hyperplasia, and degenerated muscle fibers histologically.

Hyaline degeneration, atrophy, and hypertrophy of myofibers in palatine muscle specimens was more severe in dogs effected with more severe clinical manifestations.

Separation of epidermal layer from connective tissue layer with vacuolations was a common feature. Mild increased thickness of epithelial layers indicative of edema which also causecollagen fibers to be irregularly disposed and distanced in the lamina propria.

Excretory ducts showed hyperplasia with increased dilatation and congestion. Hemorrhages were present in the palatine musculature. All blood vessels showed congestion. Hyperplasia, dilatation, basophilic 
fluid were found in the lumen of palatine salivary gland. Degeneration, necrosis of muscle fibers and fragmentation of levator muscle fiber was also a common finding in all the specimens. Excretory ducts were dilated with basophilic fluid.

Fig.1 Increased collagen connective tissue in the lamina propria and congestion of blood vessels

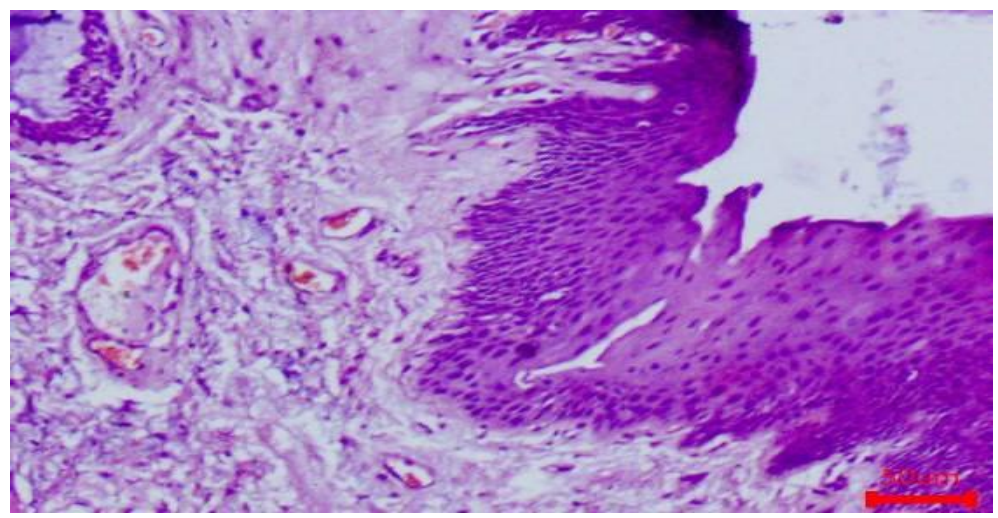

Fig.2 Mucosal epithelium thickened due to hyperplasia

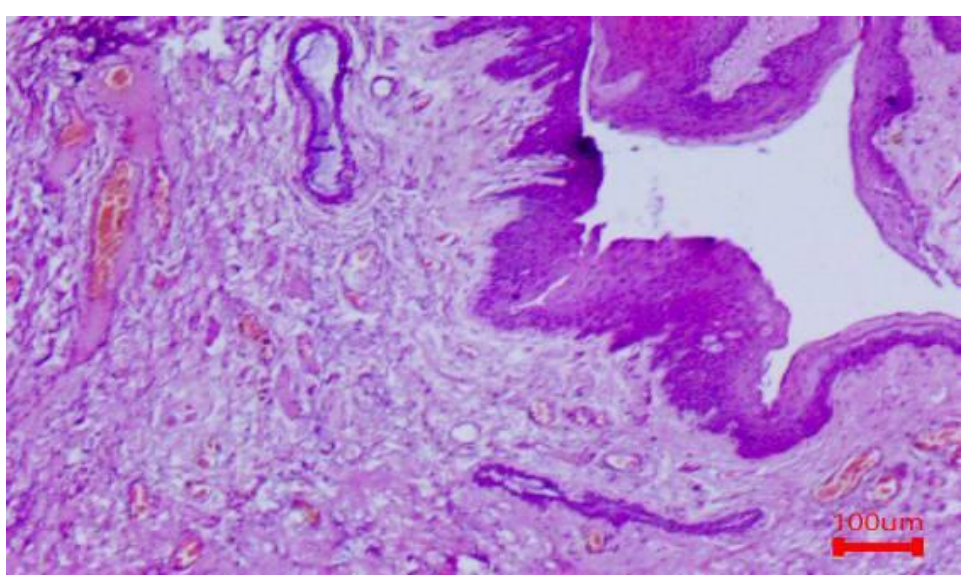

Fig.3 Interglandular mononuclear cell infiltration

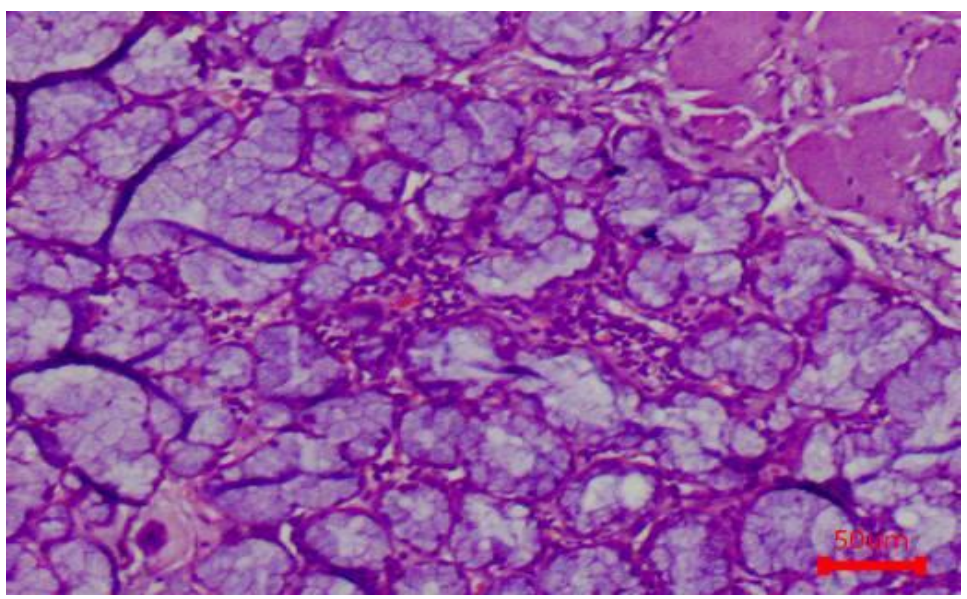


Fig.4 Levator palatine revealed degeneration and necrosis with edema, Congestion, Intestial fibrosis

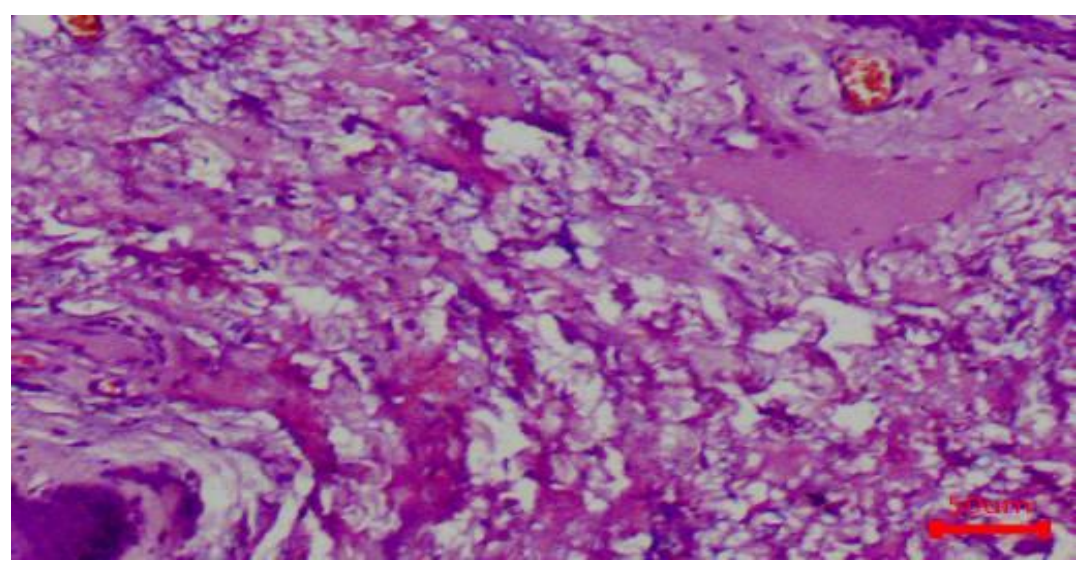

Fig.5 Multiple excretory duct revealed dilatation with mucus secretion

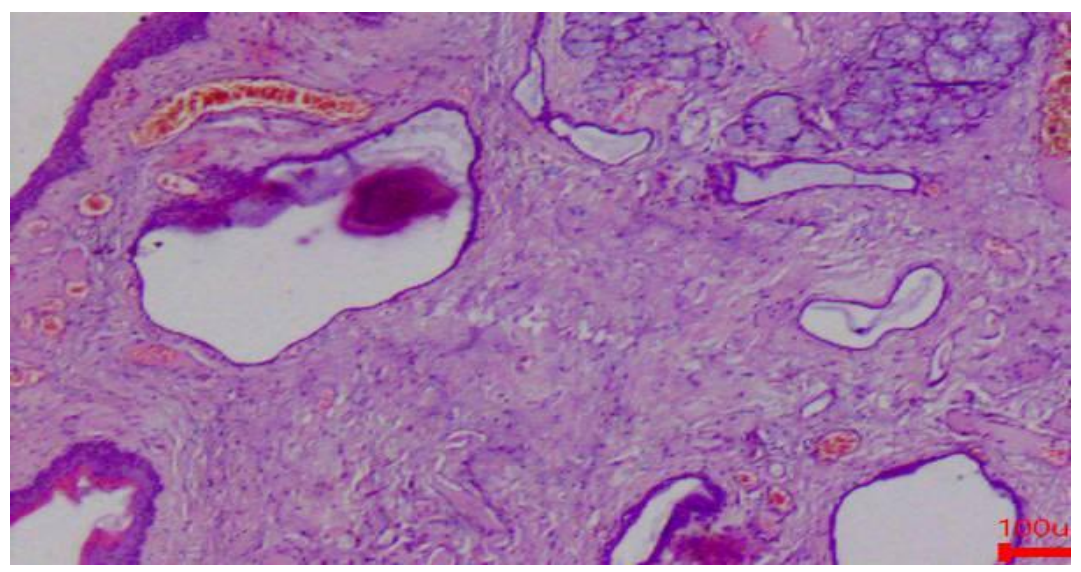

Fig.6 One excretory duct showed marked dilatation with thickening and other ducts showed dilatation

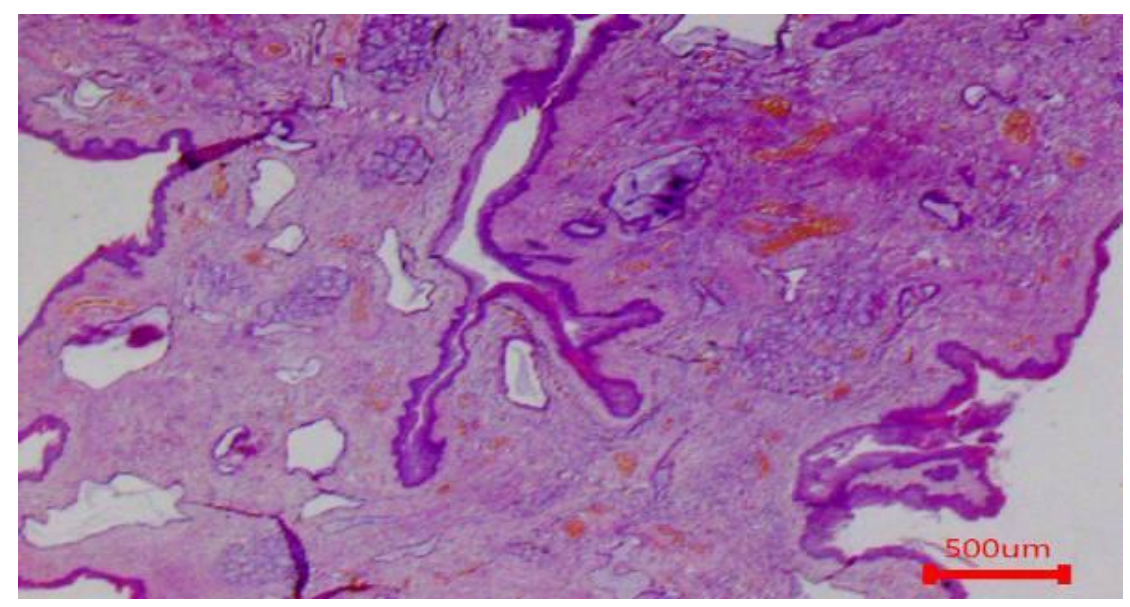


Fig.7 Hyperplasia of palatine salivary gland

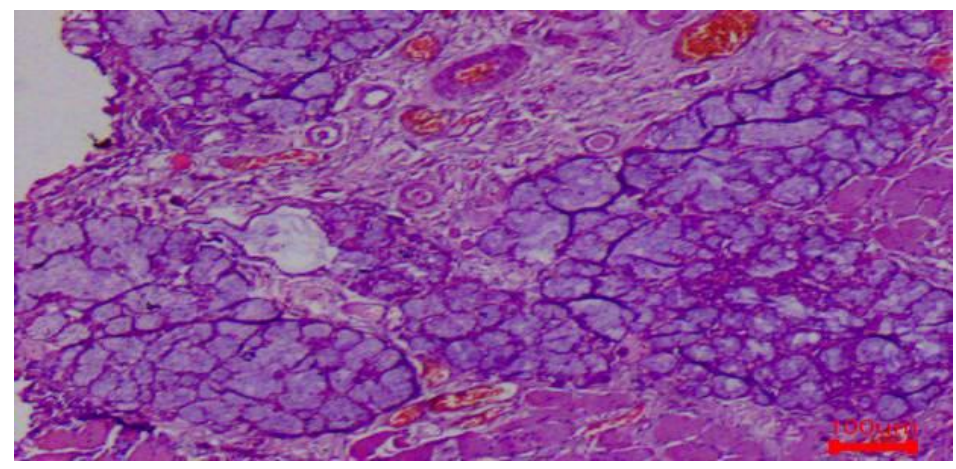

Fig.8 Moderate to severe mucosal hyperplasia resulting in thickening of mucosal epithelial lining

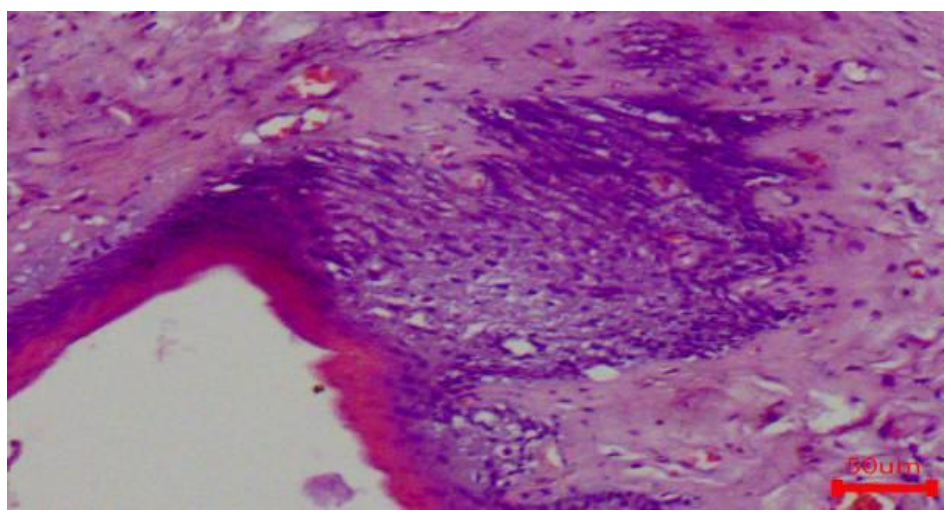

Fig.9 Degeneration and necrosis of muscle fibers

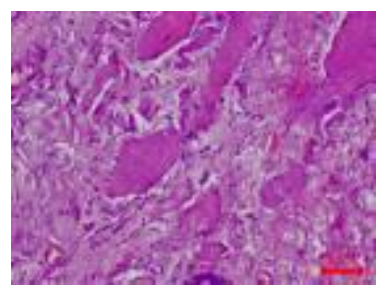

Fig.10 Central nuclei in the muscle fibers

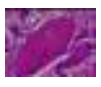

Fig.11 Hyaline degeneration of muscle fibers

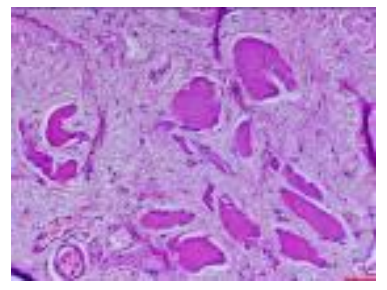


Fig.12 Dilated excretory duct with degenerating muscle fibers

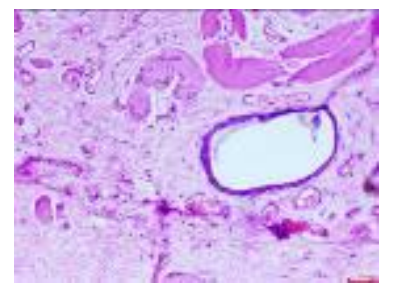

Fig.13 Dilated palatine salivary gland with hyperplesia and basoesonophilic fluid

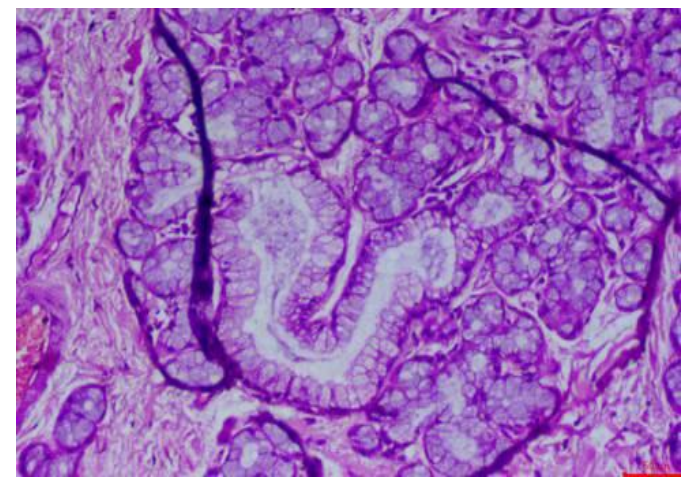

The histological study indicated that the increased thickness of the soft palate in dogs with brachycephalic airway syndrome was not due to muscle hypertrophy or fat deposition but is instead due to significantly increased stroma within the lamina propria, edema and increased proportion of salivary tissue.

In this study histologically extensive degenerative lesions involving the majority of muscle fibers of the palatine musculature were found. The findings in the present study suggest that there is continuous injury to the palatine muscles which is not seen in normocephalic dogs (Arrighi et al., 2011).

Moderate to severe mucosal hyperplasia causes thickening of the mucosal epithelial lining of the soft palate (Pichetto et al., 2015).

Irregular dispersion of collagen fibers of the lamina propria was due to edema, sub epithelial dense connective tissue in the soft palate of brachycephalic dogs (Pichetto et al., 2015).
Extensive degenerative lesions observed in palatine musculature due to persistent traumatic injury of the palatine muscles due to brachycephalic syndrome in dogs with elongated soft palate and this condition is rarely seen in normocephalic dogs which coincides with the observations of Arrighi et al., 2011.

Many dogs were under corticosteroid treatment for brachycephalic syndrome which causes weakness in muscle fiber which coincides with the observations of Khaleeli et al., 1983.

Increased amount of intercellular space with thick epithelium is considered to be the expression of edema which was also observed in obstructive sleep apnea in humans which correlates with the findings of Hamans et al., 2000 .

Hyperplasia of the palatine salivary glands was seen in all the samples for histopathological examination of soft palate. 
Airway turbulence and friction of soft palate during inspiration and snoring could represent reasonable causes for palatine gland hyperplasia to occur as defensive mechanism (Woodson et al., 1991).

The function of palatine glands is to ensure constant humidity and lubrication of the palatine mucosa, to prevent friction damage during food (Kuehn and Moon, 2005). In brachycephalic dogs, palatine gland hyperplasia together with luminal mucin accumulation compounds thickening of the soft palate

In conclusion the histological features of the brachycephalic palate were associated with muscular degeneration and atrophy of palatine muscles, combined with increased proportion of stroma and diffuse edema. The mucosal epithelial lining was thickened due to moderate to severe mucosal hyperplasia. Due to these changes in the histology of soft palate, changes in the elastic resistance coupled with progressive increase in volume of the soft palate results in the upper airway obstruction accompanied with typical clinical symptoms.

\section{Acknowledgements}

The Authors wish to thank Dr Pazhilinivel for histopathological interpretations. They also wish to thank MVCTH, Directorate of Clinics, TANUVAS, Madras Veterinary College, and Chennai-07 for constant support during the entire research.

\section{References}

Arrighi, S., Pichetto, M., Roccabianca, P. and Romussi, S., 2011. The anatomy of the dog soft palate. I. Histological evaluation of the caudal soft palate in mesaticephalic breeds. The Anatomical Record: Advances in
Integrative Anatomy and Evolutionary Biology, 294(7), pp.1261-1266.

Berger, G., Gilbey, P., Hammel, I. and Ophir, D., 2002. Histopathology of the uvula and the soft palate in patients with mild, moderate, and severe obstructive sleep apnoea. The Laryngoscope, 112(2), pp.357-363.

Davidson E.B, M.S.Davis and G.A Cambell, 2001evaluation of carbon dioxide laser and conventional incisional techniques for resection of soft palate in brachycephalic dogs.J.Am.Anima. Hosp.Assoc. 219(6): 779-781.

Gruenheid, M., Aarnes, T.K., McLoughlin, M.A., Simpson, E.M., Mathys, D.A., Mollenkopf, D.F. and Wittum, T.E., 2018. Risk of anesthesia-related complications in brachycephalic dogs. Journal of the American Veterinary Medical Association, 253(3), pp.301306.

Hamans, E.P., Van Marck, E.A., De Backer, W.A., Creten, W. and Van de Heyning, P.H., 2000. Morphometric analysis of the uvula in patients with sleep-related breathing disorders. European archives of oto-rhinolaryngology, 257(4), pp.232-236.

Khaleeli, A.A., Edwards, R.H.T., Gohil, K., McPhail, G., Rennie, M.J., Round, J. and Ross, E.J., 1983. Corticosteroid myopathy: a clinical and pathological study. Clinical endocrinology, 18(2), pp.155-166.

Koch, D.A., Wiestner, T., Balli, A., Montavon, P.M., Michel, E., Scharf, G. and Arnold, S., 2012. Proposal for a new radiological index to determine skull conformation in the dog. SchweizerArchiv fur Tierheilkunde, 154(5), p.217.

Kuehn, D.P. and Moon, J.B., 2005. Histologic study of intravelar structures in normal human adult specimens. The Cleft palate-craniofacial journal, 42(5), 
pp.481-489.

Meola, S.D., 2013. Brachycephalic airway syndrome. Topics in companion animal medicine, 28(3), pp.91-96.

Poncet, C.M., Dupre, G.P., Freiche, V.G. and Bouvy, B.M., 2006. Long-term results of upper respiratory syndrome surgery and gastrointestinal tract medical treatment in 51 brachycephalic dogs. Journal of small animal practice, 47(3), pp.137-142.

Pichetto, M., Arrighi, S., Gobbetti, M. and Romussi, S., 2015. The anatomy of the dog soft palate. III. Histological evaluation of the caudal soft palate in brachycephalic neonates. The Anatomical Record, 298(3), pp.618623.

Woodson, B.T., Toohill, R.J. and Garancis, J.C., 1991. Histopathologic changes in snoring and obstructive sleep apnea syndrome. The Laryngoscope, 101(12), pp.1318-1322.

\section{How to cite this article:}

Prakash Kumar, B., Mala Shammi, C. Ramani, Geetha Ramesh and Balagangatharathilagar. 2021. Histopathological Characterization of Soft Palate in Brachycephalic Syndrome in Pugs: A Review of 12 Cases. Int.J.Curr.Microbiol.App.Sci. 10(01): 1548-1555. doi: https://doi.org/10.20546/ijcmas.2021.1001.181 